\title{
Intensivists at night: putting resources in the right place
}

Mitchell M Levy

\begin{abstract}
During the past 50 years, caring for the critically ill has become increasingly complex and the need for an intensivist has become more evident. Management by intensivists has become a quality indicator for many ICUs. Numerous small studies have demonstrated the beneficial effect of intensivists on outcomes in the critically ill, and some clinicians have advanced the argument that a night-time intensivist is essential for the care of critically ill patients. In response, many institutions have hired full-time intensivists for both day and night coverage in the ICU. Two recent studies have been conducted that make a compelling argument for redirecting funding of night-time intensivists to areas of greater need in health care. In a retrospective analysis of a large database that involved more than 65,000 patients, no benefit of night-time intensivists could be found in ICUs where care is managed by intensivists during the day. Only in ICUs where management by intensivists is not mandated could a beneficial impact on mortality be found. The second study, a randomized controlled trial, evaluated the effect of night-time intensivists on length of stay, mortality, and other outcomes and was a negative trial. In this methodologically rigorous trial, there was no difference in outcomes between the intensivist and control group, which consisted of in-house resident coverage at night with availability by telephone of fellows and intensivists. These two robust studies clearly suggest that night-time intensivists do not improve mortality in ICUs managed by intensivists during the day. Though possibly beneficial in low-intensity environments, the widespread drive to add night-time intensivist coverage may have been premature.
\end{abstract}

\section{Introduction}

During the past 50 years, caring for the critically ill has become an increasingly complex task. New insights into pathophysiology, expensive therapeutic agents, and the proliferation of new technologies for physiologic monitoring contribute to making care of the critically ill patient a nuanced and demanding effort. Thus, the need for an intensivist, trained in the management of critically ill patients, in the ICU has become more evident. In fact, management by intensivists has become a quality indicator for many ICUs, especially high-intensity ICUs $[1,2]$. Numerous small, prospective cohort studies have demonstrated the beneficial effect of intensivists on outcomes in the critically ill [3-5]. Consequently, some clinicians have advanced the argument that a night-time intensivist is an essential ingredient for safe, high-quality care for critically ill patients [6-8]. In response, many

Correspondence: mitchell_levy@brown.edu

Warren Alpert Medical School at Brown University, Rhode Island Hospital, 593 Eddy Street, Providence, RI 02903, USA institutions have hired full-time intensivists for both day and night coverage in the ICU. Although the belief has also generated debate in the literature $[9,10]$, no robust studies that supported either position had been published until recently. Now two studies have been conducted that make a compelling argument for redirecting funding of night-time intensivists to areas of greater need in health care $[11,12]$.

Significant messages for the field are conveyed in the article by Wallace and colleagues [11], a retrospective cohort trial evaluating the presence of night-time intensivists in low- and high-intensity units. In highintensity ICUs, consults or management by critical care physicians are mandated for all admitted patients; in low-intensity ICUs, consultations by critical care physicians are not mandated.

In this large database that involved 49 ICUs and more than 65,000 patients, high-intensity daytime staffing was not associated with decreased mortality, and no benefit of night-time intensivists could be found in high-intensity ICUs. This is consistent with 
a previous report [13]. Only in low-intensity ICUs could positive effects on outcomes from night-time intensivists be found. This suggests that in ICUs where care is managed by intensivists during the day, a night shift by intensivists does not seem to improve care further. During the night, the care that was set in motion by daytime intensivists remains consistent.

The second study, a randomized controlled trial published by Kerlin and colleagues [12], evaluated the effect of night-time intensivists on length of stay, mortality, and other outcomes. The message from this study is much clearer: this was a negative trial. In this methodologically rigorous trial, there was no difference in outcomes between the intensivist and control group, which consisted of in-house resident coverage at night with availability by telephone of fellows and intensivists. It is important to recognize that this randomized trial was conducted in a single-center, large academic, high-intensity university ICU in the US, with a full complement of house staff and critical care trainees and cannot be generalized to smaller, non-teaching, or low-intensity environments.

Therefore, both studies are consistent - addition of night-time intensivists to a high-intensity ICU does not make a difference in mortality or length of stay. When critically ill patients are managed by intensivists during the day, there is no added benefit to patient outcomes with the presence of an intensivist on-site at night. In both studies, intensivists and/or fellows were on-call and available at night for management to maintain the consistency of care plans developed during daytime hours.

What are we to conclude from these trials? Although the article by Wallace and colleagues [11] suggests that in low-intensity environments outcomes are improved when care is directed by intensivists at night, the widespread drive to add night-time intensivist coverage based on an assumption of better outcomes may have been premature. According to these articles, there is no evidence to support this assertion. In both of the recent articles, the authors suggest that other, unmeasured outcomes - such as better end-of-life care, improved compliance with quality measures, and better educational opportunities for house staff and nursing staff - may be improved with the presence of night-time intensivists. In part, this is supported by two recent articles by Reinick and colleagues [14] and Almeida and colleagues [15]. However, we have to question whether this is an attempt to keep alive the belief that night-time intensivists do make a difference, and we must question whether the expense is justified by these potential outcomes.

\section{Conclusions}

These two robust studies clearly suggest that night-time intensivists do not improve mortality in ICUs managed by intensivists during the day. Perhaps it is time to stop trying to prove that a single intensivist in the unit at night has an effect on mortality. The value of a single intensivist may be more subtle, but just as important: as the leader of a team they create a safer environment that is more patient/family-centric, and that is more consistent with best practices. That value foretells considerable implications for many ICUs globally. Given the reality of spiraling costs in health care, this might be one area in which cost savings can be realized without sacrificing the quality of care our patients receive. It is time we embraced the results of these trials as reflecting the need for daytime intensivists - who apply the appropriate standard of care in order to maintain high-quality care and to redirect the resources proposed for night-time intensivists elsewhere.

Competing interests

The author declares that he has no competing interests.

\section{Published: 14 Oct 2013}

\section{References}

1. Society of Critical Care Medicine Quality Indicators Committee: Candidate Critical Care Quality Indicators. Anaheim, CA: Society of Critical Care Medicine; 1995.

2. Factsheet: ICU physician staffing (IPS). Washington, DC: The Leapfrog Group [http://www.leapfroggroup.org/media/file/FactSheet_IPS.pdf].

3. Hanson CW 3rd, Deutschman CS, Anderson HL 3rd, Reilly PM, Behringer EC, Schwab CW, Price J: Effects of an organized critical care service on outcomes and resource utilization: a cohort study. Crit Care Med 1999, 27:270-274

4. Pronovost PJ, Angus DC, Dorman T, Robinson KA, Dremsizov TT, Young TL: Physician staffing patterns and clinical outcomes in critically ill patients: a systematic review. JAMA 2002, 288:2151-2162.

5. Gajic O, Afessa B, Hanson AC, Krpata T, Yilmaz M, Mohamed SF, Rabatin JT, Evenson LK, Aksamit TR, Peters SG, Hubmayr RD, Wylam ME: Effect of 24hour mandatory versus on-demand critical care specialist presence on quality of care and family and provider satisfaction in the intensive care unit of a teaching hospital. Crit Care Med 2008, 36:36-44.

6. Burnham EL, Moss M, Geraci MW: The case for 24/7 in-house intensivist coverage. Am J Respir Crit Care Med 2010, 181:1159-1160.

7. Cartin-Ceba R, Bajwa EK: 24-Hour on-site intensivist in the intensive care unit: yes. Am J Respir Crit Care Med 2010, 181:1279-1280.

8. Lindell KO, Chlan LL, Hoffman LA: Nursing perspectives on 24/7 intensivist coverage. Am J Respir Crit Care Med 2010, 182:1338-1340.

9. Jones SF, Gaggar A: Is there a doctor in the house? The downside of 24/7 attending coverage in academic intensive care units. Am J Respir Crit Care Med 2010, 181:1280-1281.

10. Kahn JM, Hall JB: More doctors to the rescue in the intensive care unit: a cautionary note. Am J Respir Crit Care Med 2010, 181:1160-1161.

11. Wallace DJ, Angus DC, Barnato AE, Kramer AA, Kahn JM: Nighttime intensivist staffing and mortality among critically ill patients. N Engl J Med 2012, 366:2093-2101.

12. Kerlin MP, Small DS, Cooney E, Fuchs BD, Bellini LM, Mikkelsen ME, Schweickert WD, Bakhru RN, Gabler NB, Harhay MO, Hansen-Flaschen J, Halpern SD: A randomized trial of nighttime physician staffing in an intensive care unit. N Engl J Med 2013, 368:2201-2209.

13. Levy MM, Rapoport J, Lemeshow S, Chalfin DB, Phillips G, Danis M: Association between critical care physician management and patient mortality in the intensive care unit. Ann Int Med 2008, 148:801-809. 
14. Reinick A, Wallace DJ, Bernato AE, Barnato AE, Kahn JM: Nighttime intensivist staffing and the timing of death among ICU decedents: a retrospective cohort study. Crit Care 2013. in press.

15. Almeida M, Ribeiro O, Aragao I, Costa-Pereira A, Cardoso T: Differences in compliance with Surviving Sepsis Campaign recommendations according to hospital entrance time: day versus night. Crit Care 2013, 17:R79.

$10.1186 / \operatorname{cc} 13060$

Cite this article as: Levy: Intensivists at night: putting resources in the right place. Critical Care 2013, 17:1008 